\title{
Case Study on Mouse Geometry to Enhance the Human Performance and Comfort During Online Survey Task
}

\author{
Taufeeque Hasan $^{1,}$, , Mahapara Firdous ${ }^{2}$, Christopher D. Johny ${ }^{1}$ \\ ${ }^{1}$ Mechanical Department, Amity University, Haryana, India \\ ${ }^{2}$ Civil Department, Amity University, Haryana, India
}

Email address:

taufeeque25@yahoo.com (T. Hasan),mhpbht@gmail.com (M. Firdous), cdjohny@ggn.amity.edu (C. D. Johny)

${ }^{*}$ Corresponding author

\section{To cite this article:}

Taufeeque Hasan, Mahapara Firdous, Christopher D. Johny. Case Study on Mouse Geometry to Enhance the Human Performance and Comfort During Online Survey Task. American Journal of Mechanics and Applications. Vol. 5, No. 2, 2016, pp. 8-14. doi: $10.11648 /$ j.ajma.20170502.11

Received: October 30, 2016; Accepted: November 16, 2016; Published: July 18, 2017

\begin{abstract}
The feedback plays a very important role in forecasting and successful execution of any industries. To save the time, easiness, fastness, quickness, most of the firm prefer to do online survey and also to promote the online surveying. There is a revolutionary increase of online usage. Today industrial feedback, survey, the entrance exam, online teaching, tutorial became a very familiar and easy trend for education. The online preparation for the entrance exam, tutorial and even the competitive exam are also preferred to be done through on line by just clicking the option of the multiple questions. In India most of the exams like Gate, Bank Job, Railway recruitment board etc are taking the online paper for job. Hence the frequency of mouse use increases. So it becomes very important to use an ergonomically designed computer mouse so that the performance increases as well as the safety of human increases. The software programs for word processing, spreadsheet, database and graphics operations may require computer mouse use for up to two-thirds of the time. The duration of mouse use and the forces applied to the mouse by a computer operator are two risk factors that may play an important role in the development of musculoskeletal disorders [1]. The objective of the study was to compare the effect of different designs of computer mouse on human performance. The flexion of the index finger, wrist extension and ulnar deviation was measured and compared by the use of biometric software and instrument. Statistical analyses for the data was done, the results, showed that the flexion angle and time duration to complete the task were dependent on the mouse and hand geometries of subject. The wrist injuries were mostly due to awkward posture and improper support. This extension of wrist can be reduced by using the keypad and mouse of best fitted geometry.
\end{abstract}

Keywords: Human Computer Interaction, Musculoskeletal Disorders, Flexion Angle, Wrist Deviation

\section{Introduction}

Today, the use of computer in every field growing very rapidly which gives the birth to human computer interaction (HCI). The human require an input device for the interaction with the computer system. Input device of the computer systems become a critical and integral part of any humancomputer interaction system. Among lot of input devices, the most common input device used today are the computer mouse and keyboard. The invention of the mouse is commonly accredited to Douglas Engelbart and his colleagues [2]. The awareness, problem solution, learning even commercial \& non commercial firm both take the help of feedback or survey to know the reality regarding their product or their services. So that they can provide better services in the future or rectify their shortcoming so that they can stand in the present competitive atmosphere and in future too. There are lots of online job available based on surveying, data entry, form filling, and data analysis etc. Many of the house wife and other people are doing such jobs as their part time or full time job. Apart from these jobs some countries like India is moving towards digital India doing most of form filling, conducting online examination, market surveying, online preparation etc. These all activities involve the clicking of mouse button by index finger. The use of mouse 
is keep on increasing, the public are unaware of many facts that the continuous clicking of mouse button may lead to musculoskeletal disorders like tangling, tendonitis, tenosynovitis, synovitis, Ulnar nerve entrapment, carpal tunnel syndrome etc. The dose response relationship involved in the development of work related musculo-skeletal disorders (WMSDs) are unknown, but the factors involved are known to include force, posture and level of repetitiveness [3].

During data input mouse use, extensor muscle loading is more to hold the fingers over the keys [4]. Maintaining wrist and elbow postures for extended periods during typing creates static loading in the wrist extensor muscles [5]. Out of several input interfaces (e.g. keyboard, joysticks, touch pads etc.) the most common input device used today is the computer mouse. Long periods of working at a computer can increase the chance of developing an injury. Subjects reported that discomfort in their mousing hand was associated with poor wrist posture. The vertical location of the mousing surface and the provision of a wrist support also affect wrist posture. The least wrist extension occurs when the mousing surface is between $120 \%-140 \%$ of seated elbow height and when there is wrist supports present [6]. The sustained, static muscular activation patterns of the finger extensor muscles required to lift the fingers during mouse use $[4,7]$, in combination with extended wrist posture already observed from previous mouse studies $[8,9]$ may play a role in the occurrence of forearm and hand/wrist pain during intensive mouse use.

\section{Methodology}

\subsection{Task}

The task involved the preparation of questionnaire sheet. The questionnaire sheet contained a number of categories and sub- categories survey questions. Every question had a multiple choices out of which most suited will be selected by the subject by using mouse click button. A screenshot of a page of questionnaire sheet is shown in figure 1.

9. Economic Activity: Indicators Collated (Select one in each line)

\begin{tabular}{|l|c|c|c|c|}
\hline & $\begin{array}{c}\text { Town or } \\
\text { District } \\
\text { Centres }\end{array}$ & Towns & Both & Neither \\
\hline Number of jobs & $\square$ & $\square$ & $\square$ & $\square$ \\
\hline Jobs growth & $\square$ & $\square$ & $\square$ & $\square$ \\
\hline No of businesses & $\square$ & $\square$ & $\square$ & $\square$ \\
\hline Land use by type & $\square$ & $\square$ & $\square$ & $\square$ \\
\hline
\end{tabular}

10. Retail Performance: Indicators Collated (Select one in each line)

\begin{tabular}{|c|c|c|c|c|}
\hline & $\begin{array}{l}\text { Town or } \\
\text { District } \\
\text { Centres }\end{array}$ & Towns & Both & Neither \\
\hline No of retail jobs & 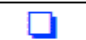 & $\square$ & & \\
\hline No of retail businesses & G & 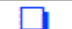 & 11 & $\square$ \\
\hline Total retail property stock & $\square$ & 3 & 1 & 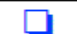 \\
\hline Retail business by type: independents/multiples & & 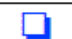 & a & \\
\hline Independent retailers: business performance & & & & \\
\hline Footfall & ] & $\mathbf{7}$ & a & 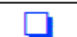 \\
\hline Rental Levels & 1 & & 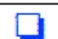 & \\
\hline Capital values \& investment yields & ] & & ] & \\
\hline Vacancy levels & $\square$ & $\square$ & $\square$ & 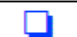 \\
\hline Requirements (retailers looking to locate) & $\square$ & $\square$ & $\square$ & $\square$ \\
\hline Planning applications & $\square$ & $\square$ & $\square$ & $\square$ \\
\hline
\end{tabular}

Figure 1. Screenshot of questions asked during surveying task. 


\subsection{Dependent Variables}

In this study two variables (time $\&$ angle) were considered as performance measuring parameters. These were time to complete the task, angular deviation of flexion of the index finger, wrist flexion/extension and radial/ulnar deviation. The null hypothesis was that these parameters had no effect on the geometry of the computer mouse.

\subsection{Subjects}

Twenty subjects were selected to perform the task. The mean age of the participants was 23.6 years and range of their age was $20-28$ years. All subject reported using their right hand to operate the computer mouse. The sitting posture of subjects and apparatus set was identical. The surface area of subject's hand was measured. Figure 2 shows the hand of the subjects and their hand dimension used in this study.

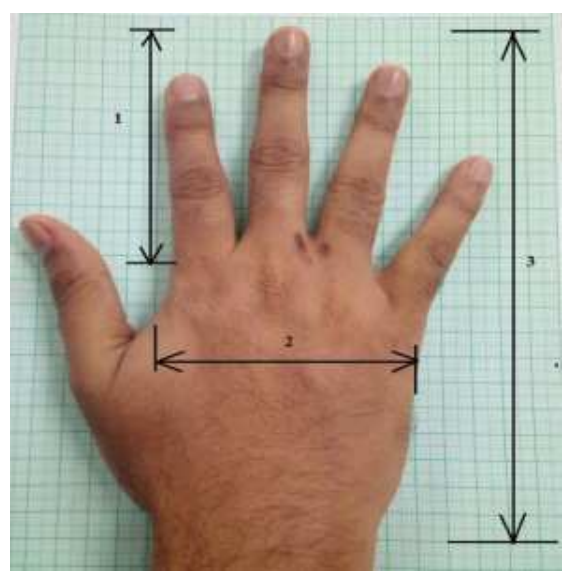

1. Index Finger, 2. Hand Width, 3. Hand Length

\subsection{Mouse Type}

Intelli mouse also known as a wheel mouse or a scroll mouse, which has a wheel between the left and right mouse buttons that enables the users to easily scroll up and down using the wheel. In India this type of mouse is the most popularly used with all new computers. The different company of intelli mouse has different geometries and specifications. Different mouse used in this study in grouped into 3 broader categories as shown in the table 1 below

Table 1. Different Mouse.

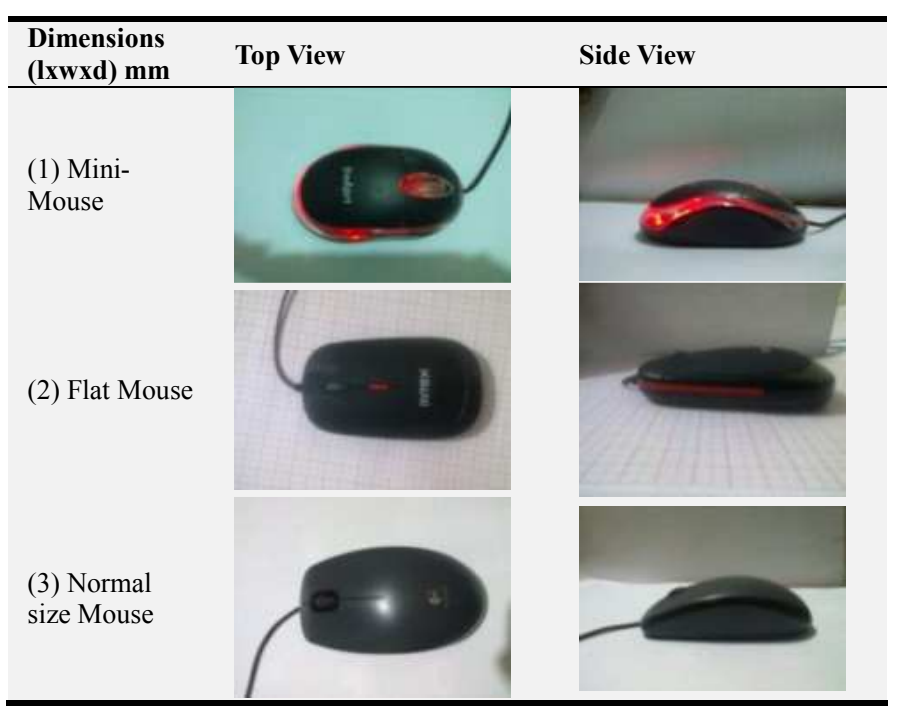

\subsection{Data Acquisition}

The connection of the component used in the experimental set up is given below.

Figure 2. Hand Geometry.

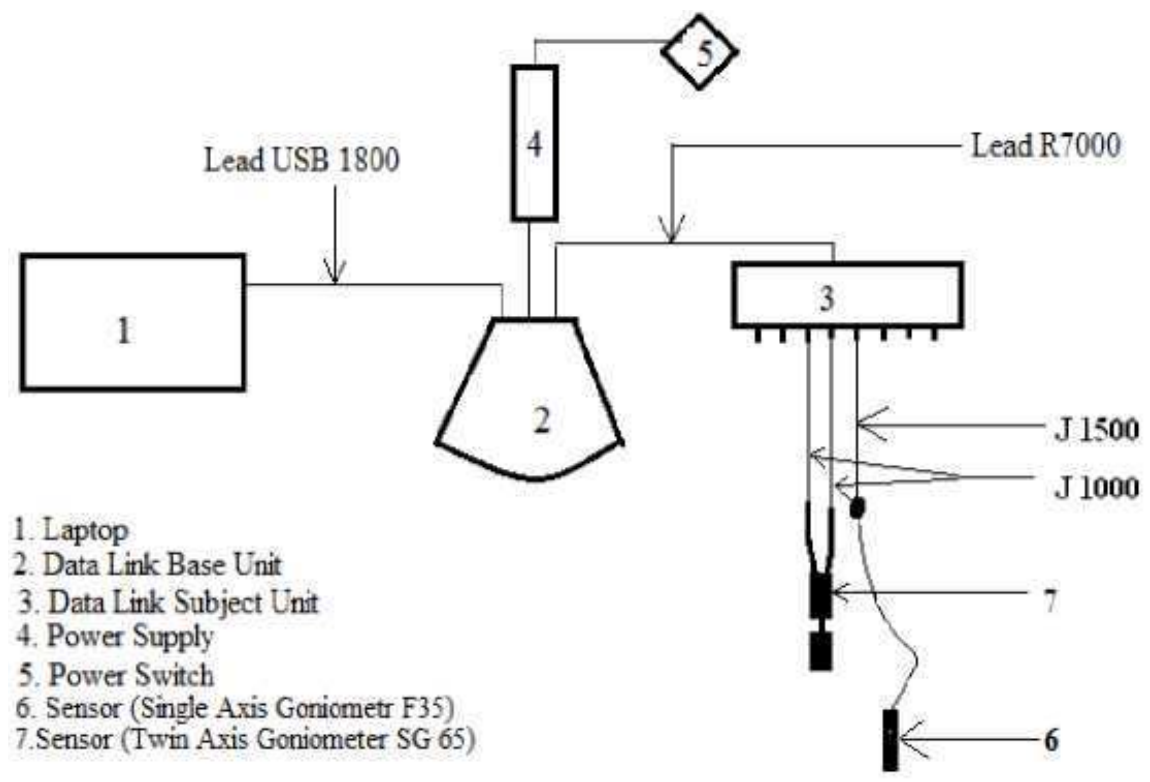

Figure 3. Layout of the experiment setup. 
Single axis goniometer Type 35 sensor was attached on the mousing hand index finger of the subject to sense the angle deviation (index finger), while twin axis goniometer (7) was attached on the wrist of the subject (shown in figure 3) to measure flexion/extension and ulnar/radial deviation of the wrist. The other end of the single axis goniometer was attached to J1500 lead, while twin axis goniometer was attached to two J1000 (one to measure flexion/extension \& other for ulnar/radial deviation). The other end of these connecting lead were connected to any three different channels out of eight available in the Data Link Subject Unit. This Data Link Subject Unit was connected to the Data link Base Unit. The Data Link Base Unit was further connected by power supply and laptop (USB port). The Data Link Software was installed in the laptop which read the muscle activity on which sensor was attached. After completion of the task the recorder was stop and saved. The reading was exported to the desired file format for further analysis, the figure 4 shows the screen shot of the data acquisition.

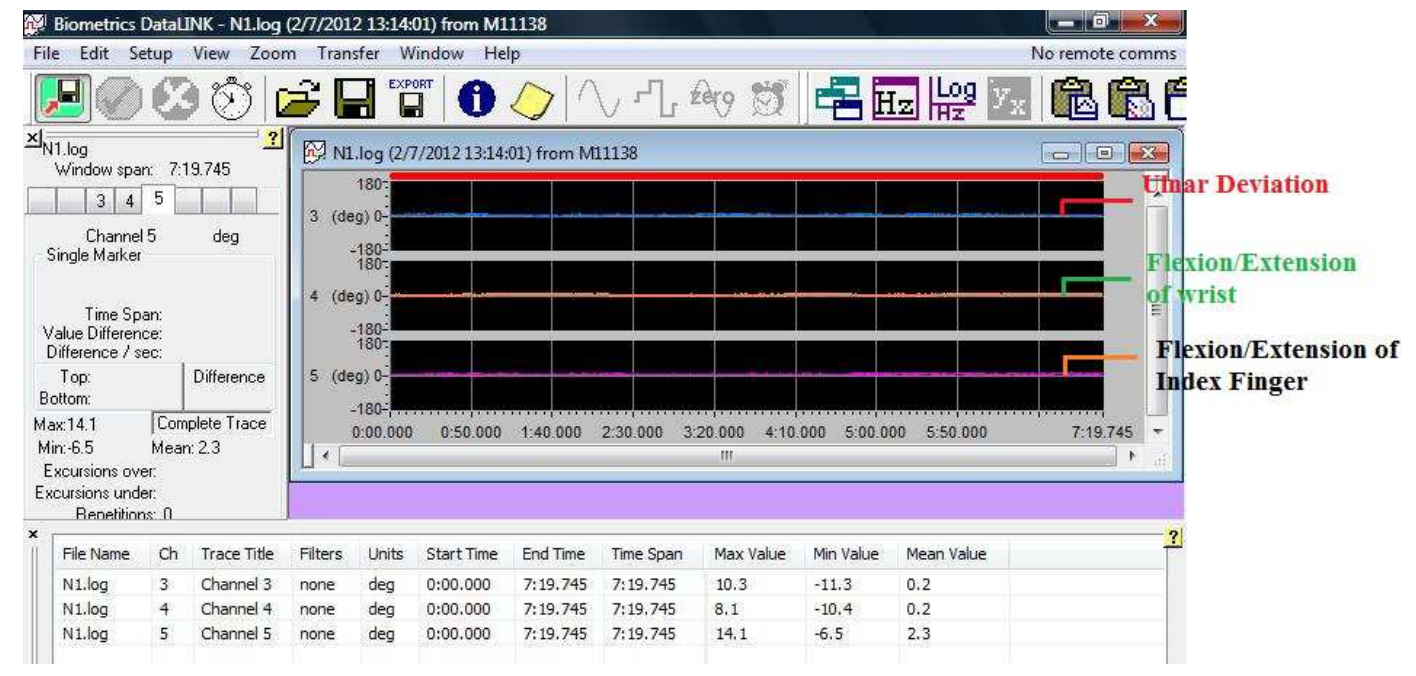

Figure 4. Screen shot of data acquisition.

\section{Apparatus Used}

\subsection{Experimental Setup}

The Study was conducted in the Ergonomics Research Division at Z. H. C. E. T, A. M. U (Aligarh, India). The set up and instrument used to record the data was shown in figure 5

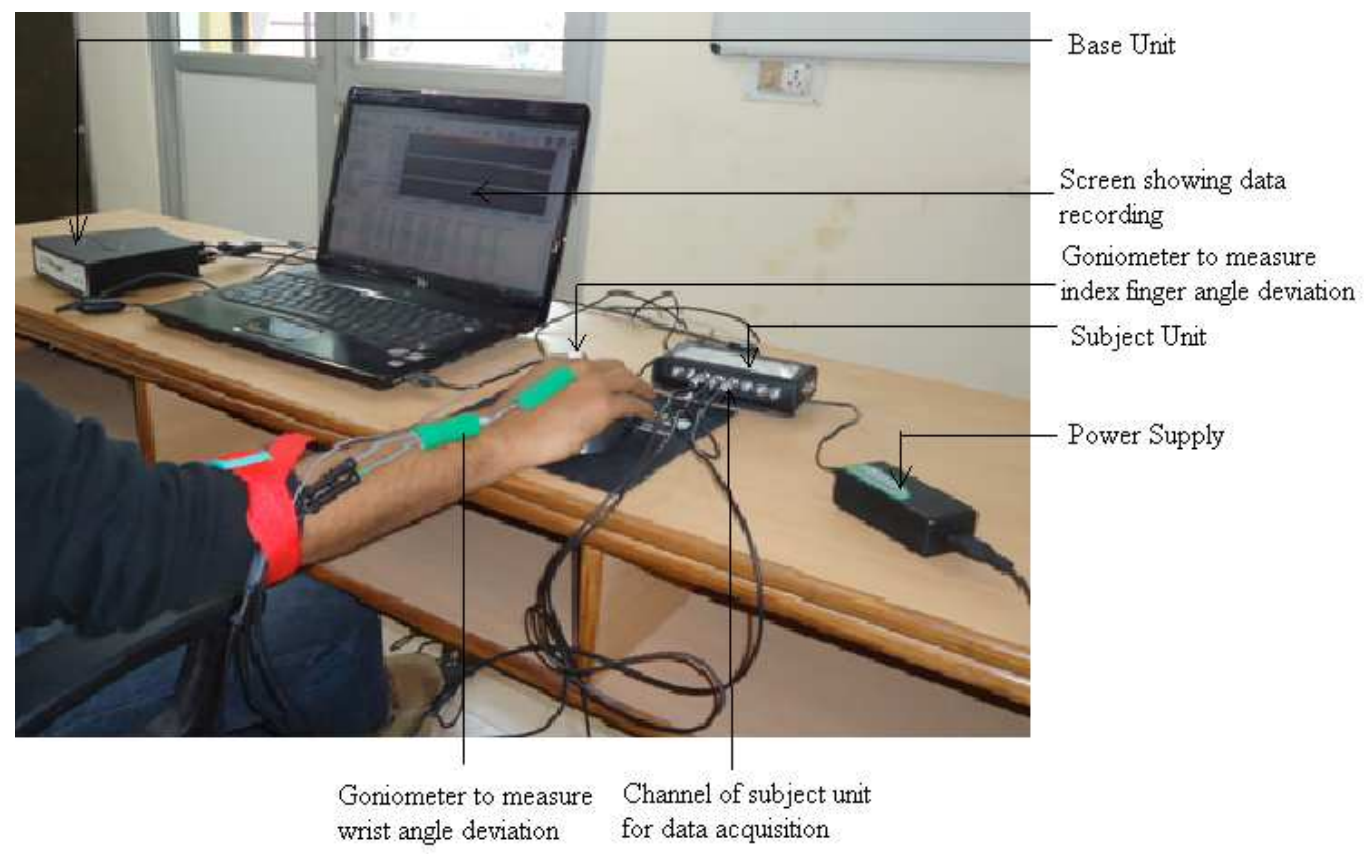

Figure 5. Experimental Setup. 


\subsection{Data Recording}

In this experiment, the Data Link software and hardware of $\mathrm{M} / \mathrm{s}$ Biometric Ltd. (UK) was used to record the muscle activity. The recording was done at the sampling rate of 100/sec using Single axis goniometer sensor (Type: F35; Make: Biometrics Ltd. UK). The signal of goniometer was interfaced on the laptop (HP based on Core2Dual Processor) using 8 channel subject unit of Data Link (DLk900: No. M11138 2009-09: Make) using R7000 Lead (Make Biometrics Ltd. UK) and then transferred to base unit after then to the laptop using connection lead (USB 1800 Make: Biometrics. Ltd. UK).

\section{Procedure}

First of all single axis goniometer type F35 sensor was attached to the selected muscles i.e. mousing hand index finger to measure the angle deviation (flexion and extension). The goniometer was fixed while the participants were sitting, elbows at $90^{\circ}$ with their index finger in the neutral position and forearms in pronation resting on the desk surface. The wrist band was locked over goniometer, so the setting must not get disturb while performing the task. Reference position $0^{\circ}$ (flexion and deviation) was defined as the index finger angles when the forearms were supported on the tabletop, elbows at $90^{\circ}$, forearms in pronation. The angular movement of index finger was measured. Also the duration of time to complete the given task was also recorded for analysis.

Each subject performed given task while seated, before starting the task, subject's hand geometry was measured. Computer, Computer peripherals, workstation and content were identical. Height of the chair, screen and mousing hand (right hand) was same for all the subjects. Subjects were allowed to adjust their chair according to their comfort level. Each subject performed the same task using each type of mouse consecutively, after a rest period of at least fifteen minutes in between two consecutive tasks so that subject get relaxed. The simultaneous comparison of the mouse was done on the basis:

(1). Angle deviation of the index finger while doing the task.

(2). Angle deviation of the wrist.

(3). Duration of time to complete the task.

\section{Results}

\subsection{Time Duration}

Table 2 shows the meantime taken to complete the task by the participants for the given experimental task. It was noticed that with decrease in size of computer mouse time to complete the task increases. The size of mouse 1 was least and mean time to complete the task was maximum (5.906 minutes).

Table 2. Mean time to complete the task.

\begin{tabular}{ll}
\hline Mouse Type & Meantime to complete task \\
\hline (1) Mini-Mouse & 5.906 \\
(2) Flat Mouse & 5.252 \\
(3) Normal size Mouse & 5.222 \\
\hline
\end{tabular}

The statistical tool was applied to compare the mouse design on the basis of task completion time. The t-test was used so that each pair of mouse can be compared individually. The table 3 shows the results of the t-test comparing the use of the mouses based on task completion time.

Table 3. Comparison of mouse for mean time taken to complete the task

\begin{tabular}{lllllll}
\hline S. No & Pair & Sample & Mean & Std. deviation & Square of error mean & p-value \\
\hline \multirow{2}{*}{ Pair 1 } & 1 & 20 & 5.9060 & 1.21962 & 0.23321342162 & 0.0163 \\
& 3 & 20 & 5.2220 & .93588 & 0.18867034734 & \\
\multirow{2}{*}{ Pair 2 } & 1 & 5 & 5.9060 & 1.21962 & 0.23321342162 & 0.0704 \\
& 2 & 5 & 5.2520 & 1.18113 & 0.26410869703 & \\
\multirow{2}{*}{ Pair 3 } & 2 & 5 & 5.2520 & 1.18113 & .52822 & 0.9295 \\
\hline
\end{tabular}

The data were analyzed at $95 \%$ confidence level. There was a significant main effect of mouse $1 \& 3$ design on task completion time.

\subsection{Angle Deviation of Wrist}

Wrist awkward posture cause wrist deviations, if extended for long duration may result in disorder. Risk factor for the wrist deviation: Ulnar deviation $>24^{\circ}$; Radial deviation $>$ $15^{\circ}$; Extension of wrist $>20.6^{\circ}$; Flexion $>20.6^{\circ}[10]$.

\subsection{Wrist Flexion/Extension}

The SPSS software was used for all statistical analysis in this study. The t-test was used to compare each pair of mouse on the basis of wrist flexion/extension angle during mousing task. The table 4 showed results of the t-test over the data of wrist extension.

Table 4. Comparison of mouse on extension of wrist.

\begin{tabular}{llllll}
\hline S. No & Pair & Sample & Mean & Std. deviation & P \\
\hline \multirow{2}{*}{ Pair 1 } & 1 & 75743 & 1.90 & 1.6614 & $<0.0001$ \\
& 3 & 169933 & 5.62 & 3.9451 & \\
Pair 2 & 1 & 75743 & 1.90 & 1.6614 & $<0.0001$ \\
& 2 & 119480 & 4.95 & 3.0216 & \\
Pair 3 & 3 & 169933 & 5.62 & 3.9451 & $<0.0001$ \\
& 2 & 119480 & 4.95 & 3.0216 & \\
\hline
\end{tabular}

The data were analyzed at $95 \%$ confidence level. Since the sample number of the pairs varies, so unpaired t-test was 
used. There was significant main effect of different mouse types on the extension of wrist. This means that the geometry of mouse has very important effect on the extension of wrist.

\subsection{Ulnar Deviation}

Table 5. Comparison of mouse on ulnar deviation of wrist.

\begin{tabular}{llllll}
\hline S. No & Pair & Sample & Mean & Std. deviation & P \\
\hline \multirow{2}{*}{ Pair 1 } & 1 & 184878 & 6.52 & 4.8665 & $<0.0001$ \\
& 3 & 138135 & 5.64 & 3.958 & \\
Pair 2 & 1 & 184878 & 6.52 & 4.8665 & $<0.0001$ \\
& 2 & 193965 & 7.16 & 5.0016 & \\
Pair 3 & 3 & 138135 & 5.64 & 3.958 & $<0.0001$ \\
& 2 & 193965 & 7.16 & 5.0016 & \\
\hline
\end{tabular}

There was significant main effect of mouse design on mean ulnar deviation. Mean ulnar deviation for Mouse 1 was $6.53^{\circ} \pm 4.87^{\circ}$, Mouse 3 was $5.64^{\circ} \pm 3.96^{\circ}$, and Mouse 2 was $7.16^{\circ} \pm 5^{\circ}$.

The data were analyzed at $95 \%$ confidence level. It was found that Mouse 3 has minimum ulnar deviation

\subsection{Flexion of Index Finger}

There was significant main effect of mouse design on mean ulnar deviation. Mean ulnar deviation for Mouse 1 was $-3.98^{\circ} \pm 4.09^{\circ}$, Mouse 3 was $-4.13^{\circ} \pm 2.74^{\circ}$, and Mouse 2 was $-2.94^{\circ} \pm 1.78^{\circ}$.

Table 6. Comparison of mouse on index finger flexion.

\begin{tabular}{llllll}
\hline S. No & Pair & Sample & Mean & Std. deviation & p \\
\hline \multirow{2}{*}{ Pair 1 } & 1 & 109622 & -3.97 & 4.0892 & $<0.0001$ \\
& 3 & 43650 & -4.130 & 2.7406 & \\
Pair 2 & 1 & 109622 & -3.97 & 4.0892 & $<0.0001$ \\
& 2 & 116302 & -2.94 & 1.7762 & \\
Pair 3 & 3 & 43650 & -4.13 & 2.7406 & $<0.0001$ \\
& 2 & 116302 & -2.94 & 1.7762 & \\
\hline
\end{tabular}

The data were analyzed at $95 \%$ confidence level. There was significant main effect on the index finger flexion

\section{Discussion}

Table 2 showed the geometry of the mouse $1 \& 3$ has significant effect on task completion time. Mouse 1 come under the category of mini mouse, which take the maximum task completion duration (5.906 minutes) and the Mouse 3 has the least completion mean time (5.222 minutes), which means the decrease in size of the mouse results in increase of task completion time.

Table 4 shows, extension of wrist has significant effect on the geometry of the mouse. This mean extension of wrist can be reduced by modifying the geometry of the mouse. The extension was minimum for the Mouse 1 and maximum for the Mouse 3 having more depth. Mouse 1 has smallest $\left(1.91^{\circ}\right)$ and Mouse 3 has largest $\left(5.63^{\circ}\right)$ extension. The smaller and flatter mouse has less wrist extension, hence reduce extensor static load [11-13].

Table 5 shows, ulnar deviation of wrist has significant effect on the geometry of the mouse. Mouse 3 has less ulnar deviation $\left(5.64^{\circ}\right)$, while Mouse 2 (flat, $14 \mathrm{~mm}$ ) has more ulnar deviation $\left(7.16^{\circ}\right)$.

Table 6 shows index finger flexion has significant effect on the geometry of the mouse. Flatter mouse 2 have less deviation $\left(-2.94^{\circ}\right)$ and Mouse 2 have the maximum $\left(-4.13^{\circ}\right)[14]$.

\section{Conclusions}

The repeated action of clicking the mouse with the index finger may cause discomfort, injuries and also effect the performance.

Meantime to complete the task increases with decrease in mouse size. Mouse 1 had minimum size take maximum meantime (5.906 minutes) to complete the task, while Mouse 3 had larger size take minimum meantime (5.222 minutes) to complete the task.

The extension angle was minimum for the Mouse 1 and maximum for the Mouse 3 having more depth. Mouse 1 has smallest $\left(1.91^{\circ}\right)$ and Mouse 3 has largest $\left(5.63^{\circ}\right)$ extension.

This study showed that $2 \%$ of the total data recording Mouse 3 was above the risk zone (wrist extension), while Mouse 2 (flat) has very low percentage (less than 0.001 ) of the total data recorded was above the risk zone.

From the above experiment it can be said that the dimension of mouse geometry play important role in efficiency. The best fitted mouse geometry increases the efficiency and decreases the risk factors. The wrist injuries were mostly due to awkward posture and improper support. This extension of wrist can be reduced by using the keypad. New mouse could be an appropriate substitution for the standard mouse without losing its positive characteristics [15] Designing an ergonomic mouse for professional computer users via scenario-based design are presented in order to decrease Work-Related Musculoskeletal Disorders (WMSDs) especially in upper limbs [16].

\section{References}

[1] Johnson, P. E., Dropkin, J., Hewes, J., and Rempel, D., 1993 Office Ergonomics.

[2] Grieco, A., et al, (1995). Work with display units '94. Elsevier Science Publishers, Amsterdam.

[3] Putz-Anderson, V., 1998. Cumulative trauma disorders: Amanual for musculoskeletal diseases of the upper limbs. Taylor \& Francis, London.

[4] Gerard, M. J., Armstrong, T. J., Foulke, J. A., Martin, B. J., 1996, Effects of key stiffness on force and the development of fatigue while typing, Am. Ind. Hyg. Assoc. J. 57, 849-854.

[5] Keir, P. J., Wells, R. P., 2002, The effect of typing posture on wrist extensor muscle loading, Hum Factors, 44, 392-403.

[6] Damann, E. A., and Kroemer, K. H. E., 1995, Wrist posture during computer mouse usage, Proceedings of the Human Factors and Ergonomics Society,Vol. 1, HFES, Santa MonicaCA, 625-629. 
[7] Sogaard, K., Sjogaard, G., Finsen, L., Olsen, H. B., Christensen, H., Motor unit activity during stereotyped finger tasks and computer mouse work, 2001, J. Electromyogr. Kinesiol, 11, 197-206.

[8] Karlqvist, L., Hagberg, M., Selin, K., 1994, Variation in upper limb posture and movement during word processing with and without mouse use, Ergonomics 37, 1261-1267.

[9] Keir, P., Bach, J., Rempel, D., 1999, Effects of computer mouse design and task on carpal tunnel pressure. Ergonomics, $42,1350-60$.

[10] Bergamasco, R., Girola, C, Colombini, D., 1998, Guidelines for designing jobs featuring repetitive tasks Ergonomics 41, 1364-1383

[11] Burgess - Limerick, R., Shemmell, J., Scadden, R., Plooy, A., 1999, Wrist posture during computer pointing device use, Clin. Biomech. 14, 280-286.
[12] Delisle, A., Imbeau, D., Santos, B., Plamondon, A., Montpetit, Y., 2004,Left-handed versus right-handed computer mouse use: effect on upper extremity posture, Appl. Ergon. 35, 2128 .

[13] Jensen, C., Borg, V., Finsen, L., Hansen, K., Juul-Kristensen, B., 1998, Christensen, H., Job demands, muscle activity and musculoskeletal symptoms in relation to work with the computer mouse, Scand. J. Work. Environ. Health, 24, 418-424.

[14] Muss, M. T., and Barrero, M., 1999, Comparative study of two computer mouse designs, Human Factors TechnicalReport/RP7992, Cornell University.

[15] Dehghan, Naser, et al., 2013, Designing a new computer mouse and evaluating some of its functional parameters, Journal of research in health sciences 14.2 132135.

[16] A. Faraji, and M. R. Farahmand, 2014, An Ergonomic Computer Mouse for Professional Designers, Applied Mechanics and Materials, Vol. 440, pp. 194-198. 